\title{
A HOMOTRANSFOBIA COMO CRIME DE RACISMO SOCIAL E O JULGAMENTO DA SUPREMA CORTE BRASILEIRA
}

\section{Daniela A. Rodrigueiro* Lívia Pelli Palumbo**}

\begin{abstract}
Resumo:
Não há legislação específica que criminalize a discriminação por orientação sexual e identidade de gênero no Brasil. Em maio de 2019, a Suprema Corte brasileira formou maioria (julgamento histórico) a favor de que a "homotransfobia"/"LGBTIfobia" seja considerada racismo, reconhecendo haver uma mora inconstitucional do Poder Legislativo em tratar do tema. O presente estudo tem como escopo discorrer sobre a importância e necessidade de criminalizar a discriminação por orientação sexual e identidade de gênero no Brasil, tendo como objetivo específico analisar os votos proferidos pelos membros do Supremo Tribunal Federal e enquadramento da conduta no conceito político-social e constitucional de racismo.
\end{abstract}

Palavras-chave: LGBTIfobia; Criminalização; Mandamento de criminalização; Supremo Tribunal Federal.

\section{HOMOTRANSPHOBIA AS A CRIME OF SOCIAL RACISM AND THE JUDGMENT OF BRAZIL'S SUPREME COURT}

\begin{abstract}
:
There's no specific legislation that criminalizes discrimination based on sexual orientation and gender identity in Brazil. In May 2019, the Brazilian Supreme Court formed a majority (historical judgment) in favor of "homotransphobia"/"LGBTIphobia" being considered racism, recognizing that there is an unconstitutional backlog of the Legislature to address the issue. This study aims to discuss the importance and need to criminalize discrimination based on sexual orientation and gender identity in Brazil, with the specific objective of analyzing the votes cast by the members of the Supreme Federal Court and framing the conduct in the political and social concept. of racism.
\end{abstract}

Keywords: LGBTIphobia; Criminalization; Commandment of criminalization; Federal Court of Justice.

\section{INTRODUÇÃO}

\footnotetext{
* Professora dos cursos de Direito do Centro Universitário de Bauru da Instituição Toledo de Ensino - ITE - e do Centro de Ciências Sociais da Universidade Estadual do Norte do Paraná - UENP. Mestre e Doutora em Sistema Constitucional de Garantias de Direitos pela Instituição Toledo de Ensino de Bauru-SP. E-mail: daniela@danielarodrigueiro.com.br; CV: http://lattes.cnpq.br/6859726004962297.

** Professora dos cursos de Direito do Centro Universitário de Bauru e da Faculdade Iteana de Botucatu, mantidos pela da Instituição Toledo de Ensino - ITE. Mestre e Doutoranda em Sistema Constitucional de Garantias de Direitos pela Instituição Toledo de Ensino de Bauru-SP. E-mail: livia.ppalumbo@ gmail.com. CV: http://lattes.cnpq.br/2243682914468717
} 
No Brasil, a par do histórico contexto de busca de proteção das minorias através da via do direito penal, e do mesmo modo, apesar da inquestionável vulnerabilidade de toda população que não se propõe a viver sobre o manto do binarismo de gênero, a homotransfobia não é tratada como crime.

Não obstante, é fato que a Carta Magna Brasileira, tendo a dignidade humana como principal fundamento, assegurou a todas as pessoas a liberdade para viver da forma que melhor escolher; bem como a igualdade, que exprime que todos devem ser tratados iguais sem quaisquer distinções, proibido ainda a discriminação de qualquer natureza e assegurando, contudo, distinção quando houver um comportamento social injusto e injustificado, devendo buscar na lei e na sua melhor aplicação, a igualdade material, como meio de proteção do grupo vulnerável - no caso do presente trabalho e mais especificamente, a população LGBTI+.

Assim, o artigo tem como objetivo analisar a questão da ausência de legislação acerca da criminalização da LGBTFOBIA no Brasil e a recente decisão do Supremo Tribunal Federal definindo tal conduta como crime de racismo. Para este desenvolvimento, um estudo sobre os direitos fundamentais, em especial à liberdade de escolha, à igualdade, à felicidade, à orientação sexual e identidade de gênero, para então, o respeito ao fundamento da dignidade humana, fundamento da República Federativa do Brasil.

Na sequência, elucidações sobre o crime de ódio e a realidade de mortes ocasionadas por tal motivo no país. Foram examinadas as votações no Supremo Tribunal Federal no Mandado de Injunção n. 4733 e na Ação Direta de Inconstitucionalidade por Omissão n. 26, que decidiram pela criminalização dos atos motivados pelo preconceito e discriminação contra a comunidade LGBTI+, expondo os votos favoráveis e contrários dos ministros.

Trata-se de uma pesquisa bibliográfica, que utiliza o método dedutivo, feita por meio da análise de livros, artigos de periódicos, jurisprudência e legislações, cujo acervo é alcançado em meio eletrônico e bibliotecas, e, em especial, pela análise dos votos dos ministros do STF.

\section{DIREITOS FUNDAMENTAIS E O DIREITO À LIVRE ORIENTAÇÃO SEXUAL E À IDENTIDADE DE GÊNERO}


A expressão "Direitos Fundamentais" remete a uma análise semântica, ou seja, ao substantivo "direitos" agregou-se o adjetivo "fundamentais", suscitando uma indagação a respeito do porquê de tais direitos, em contraponto aos demais, destacarem-se por sua fundamentalidade. Não há como se pensar em direitos fundamentais fora de um contexto generalizante, em que, de um lado, são concebidos como direitos subjetivos e, de outro, como instituições sedimentadas no tecido social e que devem condicionar ações individuais e coletivas. (NUNES JUNIOR, 2014).

A adjetivação examinada tem a clara pretensão de expor a inerência de tais direitos à condição humana, ou seja, de alçá-los à condição de direitos elementares, que remetem à própria natureza do ser humano, sendo uma dimensão objetiva dos direitos fundamentais, em que "se mostram como princípios conformadores do modo como o Estado que os consagra deve organizar-se e atuar" (GUERRA FILHO, p. 45).

Flávia Piovesan (2002, p. 41) conceitua direitos fundamentais como "uma unidade indivisível, interdependente e inter-relacionada, na qual os valores da igualdade e liberdade se conjugam e se completam".

Como afirma Haberle (1997), ao discorrer sobre a sociedade aberta dos intérpretes da Constituição, a interpretação da Lei Maior carrega intrínseca a necessidade de integração da realidade na interpretação constitucional.

Existem cinco elementos básicos e que, se harmonizados, definem direitos fundamentais: norma jurídica; dignidade humana; limitação de poder; constituição; democracia. Em breve síntese, se uma norma jurídica estiver ligada ao princípio da dignidade humana ou com a limitação do poder e for reconhecida pela Constituição Federal de um Estado Democrático de Direito como merecedora de proteção estatal especial, provavelmente se tratará de um direito fundamental (MARMELSTEIN, 2014, p. 20).

Os direitos fundamentais "correspondem aos valores mais importantes para a realização do ser humano, que se traduzem nas principais normas jurídicas da comunidade" (ROTHENBURG, 2014, p. 41). E assim “constituem uma categoria jurídica, constitucionalmente erigida e vocacionada à proteção da dignidade humana em todas as dimensões" (ARAUJO; NUNES JUNIOR, 2018, p. 179).

Como explica Marmelstein (2014, p. 20):

[...] os direitos fundamentais são normas jurídicas, intimamente ligadas à ideia de 
dignidade da pessoa humana e de limitação do poder, positivadas no plano constitucional de determinado Estado Democrático de Direito, que, por sua importância axiológica, fundamentam e legitimam todo o ordenamento jurídico.

Walter Claudius Rothenburg explana (2014, p. 53):

"Direitos fundamentais" é uma expressão contemporânea, de origem alemã
(Grundrechte), que acentua o aspecto jurídico positivo, ou seja, designa tais direitos
expressos em normas jurídicas vigentes constantes da Constituição (e eventualmente
de outras normas de valor equivalentes, que compõem o "bloco de
constitucionalidade").

Os direitos fundamentais possuem natureza poliédrica, ou seja, prestam-se à proteção do ser humano e sua liberdade que configuram direitos e garantias individuais, resguarda as suas necessidades, constituem direitos econômicos, sociais e culturais e sua preservação, referindo-se aos direitos à fraternidade e à solidariedade (ARAUJO; NUNES JUNIOR, 2018, p. 179).

A Magna Charta 1215 é citada por muitos como o documento que originou os direitos fundamentais, tendo em vista que em seu texto consagrava textos e cláusulas referindo-se à liberdade, e que hoje são tidos como direitos fundamentais, como, por exemplo, a liberdade, etc.

Ao se falar em direitos fundamentais em seu aspecto histórico, destacam-se suas três dimensões.

A primeira geração dos direitos fundamentais está pautada no pilar da liberdade e trata dos direitos individuais e políticos, no momento histórico do fim das monarquias absolutistas, em que o individuo é o titular dos direito e há dever de abstenção do Estado ante as liberdades individuais. Já os direitos de segunda correspondem à ideia de igualdade, em relação ao modelo econômico e de segregação social, em que há a prestação do Estado dos sociais, econômicos e culturais. Os direitos fundamentais de terceira geração dizem respeito à solidariedade, no pós-guerra mundial, em que a preocupação se dá com o olhar para a humanidade como valor ético e são caracterizados pelo direito à paz, ao desenvolvimento econômico, à comunicação, etc.

O Ministro Celso de Mello, relator do Mandado de Segurança 22.164/SP, que tratava sobre intervenção do Estado, em pronunciamento, explicou sobre os direitos de primeira, segunda e terceira geração:

Enquanto os direitos de primeira geração (direitos civis e políticos) - que 
compreendem as liberdades clássicas, negativas ou formais - realçam o princípio da liberdade e os direitos de segunda geração (direitos econômicos, sociais e culturais) - que se identifica com as liberdades positivas, reais ou concretas - acentuam o princípio da igualdade, os direitos de terceira geração, materializam poderes de titularidade coletiva atribuídos genericamente a todas as formações sociais, consagrando o princípio da solidariedade e constituindo um momento importante no processo de desenvolvimento, expansão e reconhecimento dos direitos humanos, caracterizados, enquanto valores fundamentais indisponíveis, pela nota de uma essencial inexauribilidade (BRASIL, 1995).

Os direitos de primeira geração são aqueles onde o Estado tem uma intervenção mínima, resguardando os direitos individuais indispensáveis à pessoa, ou seja, são os direitos de liberdade. Na segunda geração, há uma intervenção do Estado visando assegurar direitos de igualdade nos aspectos econômicos e sociais, como por exemplo, o direito à saúde, ao trabalho, à educação, à previdência social. Por último, os direitos de terceira geração são aqueles que caminham ao lado dos demais, os que contemplam uma coletividade, por exemplo, o direito à paz, ao desenvolvimento, à conservação do patrimônio histórico e cultural e qualidade do meio ambiente.

A privação de direitos fundamentais significa privar a pessoa de exercer seus direitos inerentes à sua condição humana, sendo o princípio da dignidade humana o fundamento base dos direitos fundamentais e do ordenamento jurídico, insculpido no art. $1^{\circ}$, inc. III, CF88.

Luís Roberto Barroso (2010) Historicamente, pode-se dizer que a dignidade da pessoa é um valor moral que foi absorvido pela política, passando a ser considerado um valor fundamental dos estados democráticos; posteriormente, esse valor foi absorvido pelo direito e tornou-se o princípio jurídico da dignidade da pessoa que se conhece hoje.

Para Walter Claudius Rothenburg (2014, p. 122):

A dignidade não é um direito fundamental, pois senão seria um direito preponderante, que sempre se imporia em relação aos demais. Mas a dignidade não se mede com os direitos fundamentais, com os quais não é passível de ponderação.

A dignidade humana, como valor fundamental do ordenamento jurídico, orienta a interpretação e aplicação dos dispositivos, ao adquirir maior „concretibilidade" quando de seu reconhecimento como princípio fundamental. Da mesma forma, Sarlet (2001, p. 60) leciona:

Temos por dignidade da pessoa humana a qualidade intrínseca e distintiva de cada ser humano que o faz merecedor do mesmo respeito e consideração por parte do Estado e da 
comunidade, implicando neste sentido, um complexo de direitos e deveres fundamentais que assegurem a pessoa tanto contra todo e qualquer ato de cunho degradante e desumano como venham a lhe garantir as condições existenciais mínimas para uma vida saudável, além de propiciar e promover sua participação ativa e corresponsável nos destinos da própria existência e da vida em comunhão com os demais seres humanos.

A Declaração Universal dos Direitos Humanos dispõe em seu artigo 1": "todos os seres humanos nascem livres e iguais em dignidade e em direito" (ONU, 1948).

Para Maria Berenice Dias (2016) a DUDH "afirma que carece de razoabilidade qualquer tipo de discriminação que seja atentatória à dignidade da pessoa". O princípio da dignidade humana visa garantir um mínimo de direito necessário à valorização do ser humano, sendo direito de todos o tratamento de forma digna, independente de classe social, cor, sexo, orientação sexual, etc.

\subsection{Liberdade, igualdade e felicidade}

Os direitos fundamentais da liberdade e da igualdade estão presentes no artigo $5^{\circ}$ da $\mathrm{CF} / 88$ : "Todos são iguais perante a lei, sem distinção de qualquer natureza, garantindo-se aos brasileiros e aos estrangeiros residentes no País a inviolabilidade do direito à vida, à liberdade, à igualdade, à segurança e à propriedade [...]".

Dias (2016) preceitua que "o princípio da liberdade está consubstanciado numa perspectiva de privacidade e intimidade, podendo o ser humano realizar suas próprias escolhas, isto é, o seu próprio projeto de vida".

A Carta Magna brasileira estabeleceu explicitamente o direito à liberdade, que também "compreende o direito à liberdade sexual, aliado ao direito de tratamento igualitário, independente da tendência sexual. Trata-se, assim, de uma liberdade individual, um direito do indivíduo" (DIAS, 2010).

Por conseguinte, a sociedade é livre para fazer o que não é proibido, assim, as pessoas possuem a liberdade para viverem sua orientação sexual e identidade de gênero.

$\mathrm{O}$ direito à igualdade, previsto no artigo $5^{\circ}$ e em outras disposições do texto constitucional, trata de um dos pilares estruturais da ordem constitucional, exprime o tratamento justo e igualitário para todos os cidadãos. 
Importante distinguir as dimensões da igualdade, ou seja, formal e material, sendo que a formal se refere à igualdade de direito (igualdade perante a lei), e a igualdade material à igualdade de fato (igualdade na lei), de modo que o papel da lei consiste em discriminar situações, para que então as regulamente (ARAUJO; NUNES JUNIOR, 2018, p. 153).

Uma terceira dimensão se apresenta como a acepção mais intensa de inclusão no Estado Democrático de Direito, a igualdade como respeito às pluralidades.

\begin{abstract}
Deve-se tanto tratar igualmente os desiguais quanto desigualmente os desiguais, na medida de sua desigualdade. A igualdade é presumida: quem ou o que for considerado igual a ouro deve ser igualmente tratado. $\mathrm{O}$ tratamento desigual vem (logicamente) depois, ou seja, tem de ser devidamente justificado, mas, se houver um motivo suficiente para descriminar, então o tratamento desigual impõe-se na exata medida da desigualdade, para anulá-la, diminuí-la ou compensá-la [...]. (ROTHENBURG, 2014, p. 127).
\end{abstract}

Conforme Araújo e Nunes Júnior (2010 p. 154), o princípio da igualdade encontra-se implantado quando reconhecidos e harmonizados os seguintes elementos: a) fator adotado como critério discriminatório; b) correlação lógica entre o fator discriminatório e o tratamento jurídico atribuído em face da desigualdade apontada; c) afinidade entre a correlação apontada no item acima e os valores protegidos pelo ordenamento jurídico constitucional. Para Dias (2016):

O princípio da igualdade está atrelado aos princípios da antidiscriminação e da antissubjugação, que se relacionam ao princípio da dignidade humana, devendo ser conferidos iguais direitos, iguais valores às pessoas, independente de sua condição ou orientação sexual".

A Constituição Federal em seu art. $3^{\circ}$, inciso IV, também assegurou o direito à igualdade e proibiu qualquer espécie de discriminação, incluindo a em razão de sexo. A igualdade e a liberdade se encontram constitucionalmente amparadas por disposição expressa que vedam a distinção por motivo de sexo e não apenas de gênero (DIAS, 2016).

Nesse contexto, surge o direito fundamental à felicidade. Para Dias (2016), embora o direito à felicidade não se encontre consagrado constitucionalmente e nem referido na legislação infraconstitucional, é um direito fundamental, já que o Estado tem a finalidade de assegurar a todos o direito à felicidade como uma meta social e não apenas um sonho individual, pois não há como ser feliz sem garantia de direitos mínimos.

O Ministro Celso de Mello, relator da ADPF 132/RJ e ADI 4.277/DF sobre união estável de pessoas do mesmo sexo, reconheceu o direito à felicidade e enunciou que referido 
direito decorre do princípio da dignidade humana:

Reconheço que o direito à busca da felicidade - que se mostra gravemente comprometido, quando o Congresso Nacional, influenciado por correntes majoritárias, omitese na formulação de medidas destinadas a assegurar, a grupos minoritários, a fruição de direitos fundamentais - representa derivação do princípio da dignidade da pessoa humana, qualificando-se como um dos mais significativos postulados constitucionais implícitos cujas raízes mergulham, historicamente, na própria Declaração de Independência dos Estados Unidos da América, de 04 de julho de 1776. (BRASIL, 2011).

O senador Cristovam Buarque apresentou, no ano de 2010, a proposta de Emenda Constitucional n. 19/2010 intitulada "PEC da Felicidade", com o intuito de alterar a redação do art. $6^{\circ}$ da $\mathrm{CF}$ para incluir aos direitos previstos como essenciais a busca da felicidade:

São direitos sociais, essenciais à busca da felicidade, educação, saúde, trabalho, moradia, lazer, segurança, previdência social, proteção à maternidade e à infância e assistência aos desamparados (BRASIL, Senado Federal, 2010).

A felicidade é almejada por todos, portanto deve ser o norte dos princípios constitucionais e das normas que compõe o sistema jurídico, pois as pessoas têm que assumir consciência de que se trata de um direito coletivo, não individual, e precisa ser garantido a toda a sociedade (DIAS, 2011). Dessa forma, conclui-se que o direito à felicidade consiste em um princípio constitucional implícito, proveniente da dignidade humana.

\subsection{Direito à livre orientação sexual e à identidade de gênero}

O direito à livre orientação sexual e ao reconhecimento da personalidade de acordo com a identidade de gênero está implícito no princípio da igualdade: "se todos são iguais perante a lei, sem distinção de qualquer natureza, aí está incluído o direito à livre orientação sexual" (DIAS, 2016); assim como decorre do princípio da liberdade:

[...] o direito à liberdade e indagarmos se ele abrange o direito à livre orientação sexual, devemos interpretá-lo à luz da dignidade da pessoa humana. Ora, proibir as pessoas de se relacionarem livremente é com certeza uma grande violação de direitos individuais. Seria o estado se imiscuindo em questões personalíssimas, como a intimidade e a personalidade. Além disso, padronizar uma única parcela de relacionamento marginalizaria uma parcela da população, sujeitando-o á discriminação e outras formas de violação da dignidade (SPONCHIADO, 2015). 
No âmbito internacional, a Assembleia Geral da Organização dos Estados Americanos, da qual o Brasil é um dos estados membros, por meio da Resolução 2.435/2008, aprovou a Declaração sobre Direitos Humanos, Orientação Sexual e Identidade de Gênero, a qual reafirma os princípios da universalidade, indivisibilidade e interdependência dos direitos humanos, especialmente no que diz respeito aos atos de violência contra indivíduos em razão de sua orientação sexual e identidade de gênero (DIAS, 2016).

No ano de 2011, a ONU declarou que os direitos LGBTI são direitos humanos. Por 23 votos a 19, seu Conselho aprovou resolução para promover a igualdade entre as pessoas, sem distinção por orientação sexual. Assevera que todos os seres humanos nascem livres e iguais no que diz respeito à sua dignidade e aos seus direitos, e que cada um pode se beneficiar do conjunto de direitos e liberdades, sem nenhuma distinção (DIAS, 2016).

A Comissão Internacional de Juristas e o Serviço Internacional de Direitos Humanos, formada por especialistas em legislação internacional, desenvolveram projeto com o objetivo de criar um conjunto de princípios jurídicos internacionais sobre a aplicação da legislação internacional às violações de direitos humanos, com base na orientação sexual e identidade de gênero (DIAS, 2016).

Em novembro de 2006, vinte e nove especialistas de vinte e cinco países, incluindo o Brasil, reunidos na Universidade Gadjah Mada, Indonésia, elaboraram os chamados "Princípios de Yogyakarta" sobre a "Aplicação da Legislação Internacional de Direitos Humanos em relação à Orientação Sexual e Identidade de Gênero” (DIAS, 2016).

Os chamados "Princípios de Yogyakarta" são princípios de direitos humanos aplicados a questões de orientação sexual e identidade de gênero. Afirmam normas jurídicas internacionais vinculantes, a serem cumpridas por todos os Estados, sendo cada princípio acompanhado de detalhadas recomendações aos Estados (DIAS, 2016).

Tais princípios situam-se em um cenário de valorização do ser humano e traçam orientações para a interpretação da legislação internacional de direitos humanos acerca da orientação sexual e identidade de gênero, realizado pela Comissão Internacional de Juristas e o Serviço Internacional de Direitos Humanos.

Trata-se de uma espécie de nova interpretação das normas já existentes sobre direitos humanos, a fim de aplicá-las em situações de discriminação em virtude das orientações sexuais. Devem ser efetivamente aplicados pelos Estados, uma vez que as regulamentações 
sobre direitos humanos já foram ratificadas em diversos tratados internacionais. Nada mais do que uma reinterpretação dessas legislações. (DIAS, 2016).

Portanto, são princípios de direitos humanos concernentes aos direitos relativos à orientação sexual e identidade de gênero, que devem ser cumpridos pelos Estados, pois servem como um guia de interpretação para as normas internacionais existentes.

[...] especialistas concordam que os Princípios de Yogyakarta refletem o estado atual da legislação internacional de direitos humanos relativa às questões de orientação sexual e identidade de gênero. Também reconhecem que os Estados podem ter obrigações adicionais, à medida que a legislação de direitos humanos continue a se desenvolver. (DIAS, 2016).

Foram estabelecidos os seguintes princípios:

1. Direito ao Gozo Universal dos Direitos Humanos; 2. Direito à Igualdade e à não Discriminação; 3. Direito ao Reconhecimento perante a Lei; 4. Direito à Vida; 5. Direito à Segurança Pessoal; 6. Direito à Privacidade; 7. Direito de não Sofrer Privação Arbitrária da Liberdade; 8. Direito a um Julgamento Justo; 9. Direito a Tratamento Humano durante a Detenção; 10. Direito de não Sofrer Tortura e Tratamento ou Castigo Cruel, Desumano e Degradante; 11. Direito à Proteção Contra todas as Formas de Exploração, Venda ou Tráfico de Seres Humanos; 12. Direito ao Trabalho; 13. Direito à Seguridade Social e outras Medidas de Proteção Social; 14. Direito a um Padrão de Vida Adequado; 15. Direito à Habitação Adequada; 16. Direito à Educação; 17. Direito ao Padrão mais Alto Alcançável de Saúde; 18. Proteção contra Abusos Médicos; 19. Direito à Liberdade de Opinião e Expressão; 20. Direito à Liberdade de Reunião e Associação Pacíficas; 21. Direito à Liberdade de Pensamento, Consciência e Religião; 22. Direito à Liberdade de Ir e Vir; 23. Direito de Buscar Asilo; 24. Direito de Constituir uma Família; 25. Direito de Participar da Vida Pública; 26. Direito de Participar da Vida Cultural; 27. Direito de Promover os Direitos Humanos; 28. Direito a Recursos Jurídicos e Medidas Corretivas Eficazes; 29. Responsabilização (DIAS, 2016).

Com destaque para $\mathrm{o} \mathrm{n}^{\circ} 2$ trata do direito à igualdade e à não discriminação que determina que os Estados deverão tomar as medidas adequadas para assegurar o desenvolvimento das pessoas de orientações sexuais e identidades de gênero diversas, para garantir que esses grupos ou indivíduos desfrutem ou exerçam igualmente seus direitos humanos.

Apesar de a CF não proibir a discriminação por orientação sexual e identidade de gênero expressamente, firmou a Convenção Interamericana contra toda Forma de Discriminação e Intolerância, aprovada pela Organização dos Estados Americanos em 2013 (DIAS, 2016).

$\mathrm{O}$ direito à sexualidade avança para ser inserido como um direito de terceira geração, que compreende os direitos decorrentes da natureza humana, tomados não 
individualmente, mas genericamente, solidariamente. A realização integral da humanidade abrange todos os aspectos necessários à preservação da dignidade humana e inclui o direito do ser humano de exigir respeito ao livre exercício da sexualidade. É um direito de todos e de cada um, a ser garantido a cada indivíduo por todos os indivíduos. É um direito de solidariedade, sem o qual a condição humana não se realiza.

\begin{abstract}
[...] a garantia do livre exercício da sexualidade integra as três gerações de direitos porque está relacionada com os postulados fundamentais da liberdade individual, da igualdade social e da solidariedade humana. A sexualidade diz com a personalidade humana. Seu desenvolvimento depende da satisfação de necessidades básicas tais como desejo de contato, intimidade, expressão emocional, prazer, carinho e amor. Ela é construída através da interação do indivíduo como estrutura social. O total desenvolvimento da sexualidade é essencial para o bem-estar individual, interpessoal e social. (DIAS, 2016).
\end{abstract}

Tais direitos são a garantia de reconhecimento da existência da pessoa no seio social, bem como de seus caracteres particulares, como aspectos físicos, pessoais e culturais. É o direito de ser como verdadeiramente é. Garante-se ao sujeito sua identidade, sua liberdade de expressar-se como é, clamando a si a proteção do Estado contra qualquer discriminação, violação da intimidade, ou limitação da liberdade em todas as suas formas: de expressão, de locomoção, e de exercício da própria identidade (SANCHES, 2017).

Segundo Fachin (2014, p. 50), a fundamentação encontra eco na Constituição Federal brasileira, sobretudo, por meio do princípio da dignidade humana, da solidariedade e dos diretos fundamentais. Em verdade, a dignidade da pessoa em muito está atrelada com a configuração de sua própria identidade. Uma vida digna, portanto, pressupõe o autorreconhecimento e o reconhecimento da comunidade em consonância com o reconhecimento de si mesmo.

Resta demonstrado, por conseguinte, que o direito à livre orientação sexual e à identidade de gênero constitui direitos fundamentais fundados nos princípios da liberdade e igualdade, bem como no princípio da dignidade humana.

\title{
2 CONCEITO DO CRIME DE HOMOTRANSFOBIA E AUSÊNCIA DE PREVISÃO LEGAL NO ORDENAMENTO JURÍDICO BRASILEIRO
}

A homofobia consiste na intolerância, discriminação ou qualquer manifestação de 
repúdio à homossexualidade e à homoafetividade.

Essa repulsa em relação às diferentes formas de orientação sexual representa um desrespeito às liberdades básicas garantidas pela Declaração Universal dos Direitos Humanos e pela Constituição Federal brasileira, de modo que se trata de ofensa aos direitos humanos/individuais da pessoa.

Trata-se da mais singular expressão da liberdade da pessoa que pode decidir, na fundamentalidade da sua vida privada, como pretende se relacionar, como pretende se apresentar, como pretender expressar sua subjetividade, sendo incompreensível que tal liberdade possa sofrer repulsa ou qualquer tipo de injustas limitações.

A sociedade evoluiu e, com ela, o as regras que compõem o ordenamento jurídico que servem para o controle social - devem seguir essa evolução. E, com isso, felizmente, a homossexualidade não pode mais ser considerada como doença ou distúrbio mental, uma vez que se trata da orientação sexual das pessoas, que devem ter seu direito à liberdade de expressão protegido.

Assim, a homofobia é uma violação do direito humano à liberdade de expressão individual e configura comportamento discriminatório, preconceituoso e imoral.

No Brasil, não há lei que regulamente o crime de homofobia, apesar de a Constituição Federal, a Lei Maior do ordenamento jurídico, determinar em seu artigo $3^{\circ}$, inciso IV, que constituem objetivos fundamentais da República Federativa do Brasil a promoção do bem de todos, sem preconceitos de origem, raça, sexo, cor, idade e quaisquer outras formas de discriminação.

Na sequência, prevê em seu artigo $5^{\circ}$, ainda no caput a inviolabilidade do direito fundamental da pessoa humana à liberdade e arremata, agora no inciso XLI, que "a lei punirá qualquer discriminação atentatória dos direitos e liberdades fundamentais".

Diante do modelo de Estado Democrático de Direito, o Estado brasileiro tem o papel de atuar de forma ativa para combater a discriminação e o preconceito, bem como impedir práticas sociais e ações particulares que violem a dignidade de integrantes de grupos vulneráveis e humilhados como os LGBTI's.

\subsection{A motivação do crime em razão da orientação sexual e estatísticas de mortes no}

\section{Brasil}


Em 2017, foi apurado o maior número de mortes de LGBTI+ ${ }^{+e}$ s dos últimos anos, com número total de 445, sendo 387 assassinatos e 58 suicídios. Houve um aumento de $30 \%$, visto que no ano de 2016 foram registrados no total 343 mortes. (GGB, 2017).

No ano de 2018, foram registradas 420 mortes de LGBTI+ ${ }^{\text {ee }} \mathrm{s}$ em todo o Brasil, sendo 320 homicídios, e 100 suicídios (GGB)

A maioria das mortes ocorreu no Estado de São Paulo com 58 mortes, seguido de Minas Gerais com 36, Bahia com 35 e Rio de Janeiro com 32. Os Estados que tiveram o menor número de mortes foram o Amapá, com 1 morte, seguido do Acre, Roraima e Tocantins, todos com 2 mortes registradas.

Clarividente, assim, a carência da população LGBTI+ por uma lei específica.

O ministro Celso de Mello disse que, se tratando de homofobia, o Brasil está em primeiro lugar com mais de cem homicídios por ano, isso porque foram vítimas apenas pelo fato de serem homossexuais. Esses números são ignorados e "se o poder público se agarra a padrões conservadores, o dia-a-dia cria o fato, obrigando as instituições a acordar”.

Oito estados-membros já aprovaram leis que punem a homofobia em suas estâncias administrativas, além de 112 municípios que também o fizeram. Entretanto, não é suficiente, sendo necessária uma lei específica. Nesse sentido, conforme aduzido, o Congresso Nacional, em meio a tanta omissão, teria duas opções, manter-se omisso, sujeitando-se a sanções da Comissão Interamericana de Direitos Humanos ou se manifestar a fim de aprovar uma lei que promova a igualdade e proteção aos LGBTI+ ${ }^{e e}$ s.

A Convenção Interamericana de Direitos humanos, ou Pacto de San José da Costa Rica, como também é conhecido, é um documento internacional que tem como objetivo “consolidar entre os países americanos um regime de liberdade pessoal e de justiça social, fundado no respeito aos direitos humanos essenciais, independentemente do país onde a pessoa resida ou tenha nascido".

O Legislativo brasileiro há muito tempo poderia ter aprovado uma lei para criminalizar a LGBTfobia, a questão não é nem a criação, mas sim a aprovação, haja vista a existência de diversos Projetos de Lei, enquanto isso não acontece, não há como punir um delito em face da LGBTfobia já que conforme art. 5, inc. XXXIX, CF/88 ninguém poderá ser punido sem lei anterior que o defina. Assim, a solução encontrada pela Suprema Corte brasileira foi a de legislar, de forma atípica, sem usurpar a função primordial do Legislativo, entretanto, para dar uma resposta às práticas homotransfóbicas que tem ocorrido no país. 


\section{A ANÁlise dA VOTAÇÃO E DA DECISÃo DO SUPREMO TRIBUNAL FEDERAL}

O autor da proposta na Suprema Corte brasileira, Dr. Paulo Roberto Iotti Vecchiatti (2019, p. 435) explica o teor do Mandado de Injunção (MI) 4.733, pela ABGLT, e a Ação Direta de Inconstitucionalidade por Omissão (ADO) no 26, pelo PPS:

[...] sua mora inconstitucional relativamente à criminalização da homofobia e transfobia, seu enquadramento do mandado de criminalização relativo ao racismo “(art. 5\%, XLII) e, assim, sua consideração como crime de racismo (não por "analogia in malam partem", mas pela compreensão político-social de racismo, já afirmada pelo STF relativamente ao antissemitismo no célebre $\mathrm{HC} \mathrm{n}^{\circ}$ 82.424/RS, enquanto qualquer inferiorização de um grupo social relativamente a outro, no que inequivocamente se enquadram a homofobia e a transfobia), ou, subsidiariamente, não consideradas como espécies do gênero racismo, sua consideração no mandado de criminalização relativo ao dever de punição [obviamente eficiente] de toda discriminação atentatória a direitos e liberdades fundamentais (art. $5^{\circ}, \mathrm{XLI}$ ), no que, aqui incontestavelmente, a homofobia e a transfobia se enquadram.

O autor continua a explicar que:

[...] no crime já positivado de discriminação por raça (art. 20 da Lei Antirracismo Lei Federal $n^{\circ}$ 7.716/89, lembrando que no famoso caso do antissemitismo, o STF bem destacou que tanto o art. $3^{\circ}$, IV, da Constituição quanto a Lei Antirracismo falam em "raça" e "cor" em palavras diferentes, de sorte a não se poder limitar o $\underline{\text { racismo unicamente à discriminação fenotípica, por cor de pele) (grifo nosso) }}$ (VECCHIATTI, 2019, p. 435).

Em histórica votação, o Supremo Tribunal Federal Brasileiro determinou, por oito votos favoráveis e três contrários, que a discriminação por orientação sexual e identidade de gênero passe a ser considerada uma prática criminosa e, assim, aprovou o uso da lei de racismo para punir a homofobia e a transfobia.

Dos onze ministros do Supremo Tribunal Federal, dez reconheceram a demora inconstitucional do Legislativo em tratar do tema, sendo que o ministro Marco Aurélio Mello foi o único que discordou.

Diante desta omissão do Poder Legislativo, a maioria do STF (8 ministros) determinaram que a conduta de homofobia e transfobia passe a ser punida pela Lei de Racismo - Lei no 7.716/89 - que prevê crimes de discriminação ou preconceito por "raça, cor, 
etnia, religião e procedência nacional”.

A decisão foi tomada na votação do dia 13 de junho de 2019, sendo os oito votos favoráveis dos ministros: Alexandre de Moraes, Carmen Lúcia, Celso de Mello, Edson Fachin, Gilmar Mendes, Luís Barroso, Luiz Fux e Rosa Weber.

E os três votos contrários dos ministros Ricardo Lewandowski, Marco Aurélio e Dias Toffoli, com argumento de que isso criaria um novo tipo de crime, o que caberia exclusivamente ao Congresso Nacional.

Mas esse não é o melhor entendimento uma vez que não se trata da criação de nenhum tipo penal, tampouco de aplicação extensiva ou analógica de delitos já previstos. Esclareceremos:

O crime de racismo está previsto no artigo 20 da Lei $\mathrm{n}^{\circ}$ 7.716/1989 sendo ele crime inafiançável e imprescritível por força da própria dicção constitucional. Ou seja, o sistema de justiça penal que reveste o reconhecimento desses delitos é de consequências muito graves para aquele que infringe a norma, que pratica tal conduta criminosa.

Dada a complexidade da questão, a matéria sub judice proporcionou intenso debate no Supremo Tribunal Federal, realizado, após o inicio do julgamento em plenário, ainda por longos três meses, com suspensão por duas vezes e o total de seis sessões para sua conclusão.

O julgamento teve início em 13 de fevereiro de 2019, momento em que foram ouvidos os autores de dois processos, quais sejam: a Ação direta de inconstitucionalidade por omissão no 26 e o Mandado de Injunção nº 4733.

Conforme julgamento da Suprema Corte Brasileira (STF, 2019), o decano, ministro Celso de Mello, relator da Ação Direta de Inconstitucionalidade por Omissão (ADO) $n^{\circ} 26$, avaliou que o Congresso Nacional não ter legislado sobre o assunto é "evidente inércia e omissão" e propôs que não seja fixado um prazo para que o Legislativo edite uma lei (como fora pedido nas ações), mas que, enquanto isso não acontecer, que a homotransfobia seja tratada como um tipo de racismo.

Para o ministro Celso de Mello, o conceito de racismo aplica-se à discriminação contra grupos sociais minoritários (um dos pontos da discussão).

O ministro Edson Fachin (relator do Mandado de Injunção no 4733) concordou com o ministro Celso de Mello e também defendeu a aplicação da Lei de Racismo até a edição de norma específica criminalizando a homotransfobia (STF, 2019).

O ministro Luís Roberto Barroso argumentou que a vontade do Congresso deve 
prevalecer, entretanto, em situações nas quais não há atuação do Legislativo, o Supremo Tribunal Federal é legítimo para fazer valer o que está na Constituição.

A ministra Carmen Lúcia defendeu que a Constituição Federal - que prevê a garantia dos direitos fundamentais de cada indivíduo- não pode ser "mera folha de papel" e que todo preconceito é violência.

Nesta mesma linha, a ministra Rosa Weber que desde o tempo da redemocratização o que se observa é verdadeira omissão legislativa em relação à proteção das pessoas LGBTI+. Que estaríamos diante de omissão legislativa inconstitucional apta a impedir a efetividade das normas constitucionais a esta parcela da população brasileira.

O ministro Fux recordando a lição de Bickel, alertou a função contra majoritária do judiciário e, portanto, do STF quando se faz necessária a proteção especial das minorias. Destacou também a doutrina de Axel Honneth donde se extrai que a criminalização de condutas que expõe grupos sociais minoritários e vulneráveis, acaba por impor uma revisão de paradigmas sociais, tem a capacidade de alterar a cultura dominante e opressora; consequentemente a menor exposição e menor vulnerabilidade autorizam o aumento da autoestima desses grupos historicamente oprimidos, permitindo a inserção social e assim o nivelamento social.

E foi neste diapasão, precedido de um verdadeiro giro no entendimento da Procuradoria-Geral da República [emanados em nos pareceres de ambas as demandas] que em maio de 2019 se consolidou a maioria necessária para o provimento das ações e em junho o julgamento fora concluído definitivamente.

Resta esclarecer que, tal qual os noticiados pareceres, os votos dos ministros que julgaram procedentes as demandas, em tempo algum entenderam pela criação de um novo tipo penal, o que efetivamente não ocorreu, tampouco se pode afirmar ou extrair como conclusão dos votos que se estaria reconhecendo analogia in malam partem.

E isto por que o entendimento majoritário da corte suprema considerou a tese da interpretação conforme a Constituição Federal de 1988 para conferir ao conceito de raça (enquanto elementar do tipo penal) não a acepção biológica, mas sim a sua dimensão político e social.

Esse entendimento fora possível através do reconhecimento do precedente esposado no Habeas Corpus n. ${ }^{\circ} 82.424 / \mathrm{RS}$, que de forma inédita na jurisprudência brasileira consagra a ideia de racismo social, permitindo que agora se estabeleça a incriminação da homotransfobia, 
nos preceitos legais apontados na lei de racismo, justamente em face do reconhecimento preliminar da omissão legislativa.

Assim, a discriminação de gênero e orientação sexual, respectivamente a homofobia e a transfobia, são, portanto, crimes de racismo uma vez que assim é considerado todo o tratamento preconceituoso e discriminatório de grupos sociais quando considerados uns em face dos outros.

Reiteramos que não se trata de interpretação extensiva ou analógica, mas de interpretação conforme a constituição através do noticiado conceito político-social que esta pautado em elementos culturais, históricos, sociológicos e antropológicos, sendo este o espírito da Constituição conforme declarado no voto do Ministro Nelson Jobim no HC $\mathrm{n}^{\circ}$ 82.424/RS:

[...] No debate da Constituinte, registrado nos anais, falava-se no negro, mas estavam lá os judeus, estavam lá os homossexuais e tivemos a oportunidade de discutir isso. [...] circularam dentro da Assembleia Constituinte todas as minorias que poderiam ser objeto de racismo. Nunca se pretendeu, com o debate, restringir ao negro. Não há necessidade de trazer esse debate, porque a Assembleia Constituinte não vai restringir, no texto, ao negro, mas vai deixar em aberto para o exercício futuro de virtuais racismos não conhecidos no momento de 88 e que possam ser conhecidos num momento do ano de 2000" (STF, HC n. ${ }^{\circ}$ 82.424-2/RS, confirmação de voto do Ministro Nelson Jobim, p. 04).

Assim, desde então, a homotransfobia passa a ser classificada como ato criminoso tendo a corte suprema, ainda que em eventual decisão contra majoritária, protegido de modo efetivo a população LGBTI+ vulneravelmente exposta pela cultura de ódio e repulsa que vem dominando a sociedade e de forma institucionalizada.

\section{CONSIDERAÇÕES FINAIS}

O presente artigo analisou a decisão do Supremo Tribunal Federal ao reconhecer que a homotransfobia é crime de racismo.

Defende-se aqui a posição da Suprema Corte brasileira ao decidir ainda que de forma atípica, em razão da ausência de norma regulamentadora, pela recepção da homotransfobia como crime de racismo (diante de seu conceito político e social e não estritamente biológico) 
ao reconhecer a omissão do Congresso Nacional.

Enquanto perdurar a omissão do Poder Legislativo, o Supremo Tribunal Federal pode decidir e decidiu por uma regra provisória para que a conduta da homotransfobia já seja considerada crime de racismo, mesmo antes de haver lei aprovada pelo Poder Legislativo e, assim, efetivamente uma proteção dos direitos fundamentais à liberdade, igualdade - na sua acepção plural, felicidade, à livre orientação sexual e identidade de gênero, pois, somente com essa proteção, há o respeito ao fundamento da República Brasileira, qual seja, a dignidade humana.

\section{REFERÊNCIAS BIBLIOGRÁFICAS}

ARAUJO, Luiz Alberto David; NUNES JUNIOR, Vidal Serrano. Curso de Direito Constitucional. 22. ed. São Paulo: Verbatim, 2018.

BARROSO, Luís Roberto. A Dignidade da Pessoa Humana no Direito Constitucional Contemporâneo: Natureza Jurídica, Conteúdos Mínimos e Critérios de Aplicação. Versão provisória para debate público. Mimeografado, dezembro de 2010.

BRASIL. Supremo Tribunal Federal. Ação Direta De Inconstitucionalidade Por Omissão 26 Distrito Federal. Disponível em:

http://www.stf.jus.br/arquivo/cms/noticiaNoticiaStf/anexo/ADO26votoMAM.pdf. Acesso em: 10 jul. 2019.

Habeas Corpus no 82.424-2 RS. Disponível em:

http://www.sbdp.org.br/arquivos/material/399_Ellwanger\%20-

$\% 20$ Voto\%20Marco\%20Aurelio.pdf. Acesso em: 10 jul. 2019.

. STF enquadra homofobia e transfobia como crimes de racismo ao reconhecer

omissão legislativa. Disponível em:

http://portal.stf.jus.br/noticias/verNoticiaDetalhe.asp?idConteudo=414010. Acesso em: 10 jul. 2019.

CORBO, Wallace. Racismo sem raça? Criminalização da homotransfobia e a invisibilização da negritude. Jota. 27 mai. 2019. Disponível em: https://www.jota.info/opiniao-eanalise/artigos/racismo-sem-raca-criminalizacao-da-homotransfobia-e-a-invisibilizacao-danegritude-

27052019?fbclid=IwAR0xO8BvFmn5OwrQteeafSrhp2p0qA147v8LgQNJVjgbdfl1d8woA2z mWfc. Acesso em: 02 jul. 2019.

DIAS, Maria Berenice. Homoafetividade e os Direitos LGBTI. 2. ed. em e-book baseada na 3. ed. impressa. São Paulo: Revista dos Tribunais, 2017. 
GUERRA FILHO, Willis Santiago. Processo Constitucional e Direitos Fundamentais.4. ed. São Paulo: RCS.

FACHIN, Luiz Edson. O corpo do registro no registro do corpo: mudança de nome e sexo sem cirurgia de redesignação. Revista Brasileira de Direito Civil, Belo Horizonte, v. 1, jul/set 2014, p. 36-60, ISSN 2358-6974. Disponível em:

<https://rbdcivil.ibdcivil.org.br/rbdc/article/view/130/126>. Acesso em: 10 jul. 2019.

Haberle, Peter. Hermenêutica Constitucional: a sociedade aberta dos intérpretes da Constituição - contribuição para a interpretação pluralista e procedimental da Constituição. Trad. Gilmar Ferreira Mendes. Sergio Antonio Fabris: Porto Alegre, 1997.

MARMELSTEIN, George. Curso de Direitos Fundamentais. 2. ed. São Paulo: Atlas, 2009.

NUNES JÚNIOR, Vidal Serrano. A cidadania social na Constituição de 1988: Estratégia de Positivação e Exigibilidade Judicial dos Direitos Sociais. São Paulo: Verbatim, 2014.

PIOVESAN, Flávia. Direitos Humanos e Direito Constitucional Internacional. 5. Ed. São Paulo: Mas Limonad, 2002.

PRADO, Marco Aurélio Máximo; JUNQUEIRA, Rogério Diniz. Homofobia, Hierarquização e Humilhação Social. In: VENTURI, Gustavo; BOKANY, Vilma (Org.). Diversidade Sexual e Homofobia no Brasil. São Paulo: Editora Fundação Perseu Abramo, 2011. P. 51-72.

ROTHENBURG, Walter Claudius. Direitos Fundamentais. São Paulo: Método, 2014.

SARLET, Ingo Wolfgang. Dignidade da pessoa humana e direitos fundamentais na Constituição Federal de 1988. Porto Alegre: Livraria do Advogado, 2001.

; MITIDIERO, Daniel. Curso de Direito Constitucional. 5. ed. em ebook. São Paulo: Saraiva, 2016.

SUPREMO TRIBUNAL FEDERAL. STF enquadra homofobia e transfobia como crimes de racismo ao reconhecer omissão legislativa. 13 jun. 2019. Disponível em:

http://www.stf.jus.br/portal/cms/verNoticiaDetalhe.asp?idConteudo=414010. Acesso em: 02 jul. 2019

VECCIATTI, Paulo Roberto Iotti. Constituição Dirigente e Concretização Judicial das Imposições Constitucionais ao Legislativo: a eficácia jurídica positiva das ordens constitucionais de legislar em geral e dos mandados de criminalização em particular. Bauru: Spessoto, 2019.

. Racismo homotransfóbico e a população LGBTI como um grupo racializado. Jota. 28 mai. 2019. Disponível em:

https://www.jota.info/paywall?redirect_to=//www.jota.info/opiniao-e-analise/artigos/racismohomotransfobico-e-a-populacao-lgbti-como-um-grupo-racializado-

28052019?fbclid=IwAR2mED4Yvnj7KoTHV5CTkXxL_ADhSKi5L4jwnlvm1wZmp3tIB33 
AVbL8_Pc. Acesso em: 02 jul. 2019.

. Maioria histórica do STF considera homotransfobia como crime de racismo.

Respostas a críticas. Justificando. 27 mai. 2019. Disponível em:

http://www.justificando.com/2019/05/27/maioria-historica-do-stf-considera-homotransfobiacomo-crime-de-racismo-respostas-acriticas/?fbclid=IwAR0wfT xrbgSLRHwBQvIqrSQMrRfgWerZU307uih9EvV0UgHqieeow6lb2I. Acesso em: 02 jul. 2019. 